\title{
4. Biopiracy and the Innovations of Indigenous Peoples and Local Communities
}

\author{
Daniel F. Robinson
}

\section{Introduction}

Biopiracy is a divisive term, and deliberately so. The original proponent of the term, Pat Roy Mooney of the NGO Action Group on Erosion Technology and Concentration (ETC), has previously stated that '[w] hatever the will and wishes of those involved, there is no "bioprospecting". There is only biopiracy." ${ }^{\prime 1}$ He explains that without adequate international laws, standards, norms and monitoring mechanisms, the theft of indigenous and local knowledge will accelerate in the years to come.

Although exaggerated for emphasis, Mooney's statement reflects a strong discontentment that was particularly prevalent in the 1990s and early 2000s amongst sections of the NGO community, many farmer's groups and indigenous communities. In the absence of adequate international standards, many bioprospecting activities in recent years have been heavily criticised, and relatively few have been widely considered to be 'fair and equitable'. However, it is very difficult to quantify the regularity and impacts of incidents that might be described as 'biopiracy'. The lack of clear definitions from any authoritative source has also given rise to confused understandings of bioprospecting, biopiracy and '[access and] the fair and equitable sharing of benefits'. The highly significant international agreement on the 2010 Nagoya Protocol on Access to Genetic Resources and the Fair and Equitable Sharing of Benefits Arising from their Utilization (Nagoya Protocol) to the Convention on Biological Diversity (CBD) may help resolve some of these ambiguities, but it has fallen short on at least one front - the section on monitoring, which is sandwiched within the compliance articles. Negotiators had the opportunity to include patent offices as checkpoints for the monitoring of access and benefit sharing (ABS) - a potentially critical inclusion for the prevention of patent-based biopiracy yet it was dropped late in the negotiations as part of the compromise that has been achieved in the Nagoya Protocol. Given that the exploitation of traditional knowledge by innovations registered through the patent system has been one of the main perceived injustices, leading to the creation and use of the term biopiracy, this is a considerable gap in the Protocol.

1 P R Mooney, 'Why We Call It Biopiracy' in H Svarstad and S Dhillion (eds), Bioprospecting: From Biodiversity in the South to Medicines in the North (Spartacus Forlag, 2000) 37. 
This chapter takes the polemical issue of biopiracy as a starting point, and explores the concepts of innovation and traditional knowledge within specific cases of bioprospecting and/or biopiracy (depending upon how or from where you view them). Specifically, the chapter demonstrates the flawed tendency by academics and policy-makers to perpetuate the 'traditional knowledge' and 'modern/scientific knowledge' dualism. A more useful focus of analysis is indigenous peoples' innovations, or at least their contributions to innovation (as described in Article 8(j) of the CBD), which may have helped to short-cut the research and development (R\&D) process. Last, the chapter examines how 'traditional knowledge', used in a number of case-study 'inventions'/discoveries that are protected by intellectual property (IP) rights (typically patents and plant breeder's rights), might be treated differently if it was described and recognised as 'indigenous innovation'.

\section{Biopiracy Typology}

Biopiracy is a discursive tool that both describes an injustice and is used for political leverage. Although the colonial enterprise of plant and animal collection has been going on for centuries, the biopiracy discourse has emerged as a powerful counter to the perception of new hegemonies imposed by IP rules with global reach, such as the World Trade Organization (WTO) Agreement on Trade-Related Aspects of Intellectual Property Rights (TRIPS Agreement). Along with the biopiracy discourse has come lobbying for additional rights, particularly for indigenous peoples, including ideas for sui generis IP rights which must compete with an already competitive suite of private commercial rights that have come to be described as 'intellectual property'. ${ }^{2}$ Lobbying for additional third-generation rights which we might call 'bio-cultural' rights of indigenous and local peoples has been comparatively more successful in forums such as the CBD, where we now see the United Nations Declaration on the Rights of Indigenous Peoples (UNDRIP) influencing the text of the Nagoya Protocol towards recognition of indigenous customary laws (Article 12). ${ }^{3}$

These developments and associated lobbying are deliberately targeted towards the issue of biopiracy, even if international forums are unable to address that issue directly. For example, in the absence of a definition of biopiracy, international organisations are left without an appropriate term to describe the specific or perceived injustices. In this void, delegates to the various agreements such as the CBD, or organisations such as the WTO, commonly use the term. For example:

2 P J Heald, 'Rhetoric of Biopiracy' (2003) 11 Cardozo Journal of International and Comparative Law 519.

3 K Bavikatte and D F Robinson, 'Towards a People's History of the Law: Biocultural Jurisprudence and the Nagoya Protocol on Access and Benefit Sharing' (2011) 7(1) Law, Environment and Development Journal 35. 
One of the measures adopted [in Peru] was the creation of the National Anti-Biopiracy Commission, whose basic task is to develop actions to identify, prevent and avoid acts of biopiracy which involve biological resources of Peruvian origin and traditional knowledge of the indigenous peoples of Peru. ${ }^{4}$

More politely, the delegates also use the term misappropriation, yet this usually has a more limited connotation regarding failure to comply with ABS laws or principles. The Secretariat of the World Intellectual Property Organization (WIPO) has utilised the work of the Intergovernmental Committee on Intellectual Property and Genetic Resources, Traditional Knowledge and Folklore (IGC) for development of Draft Policy Objectives and Core Principles for the Protection of Traditional Knowledge $e^{5}$ wich provides principles against misappropriation:

Any acquisition or appropriation of traditional knowledge by unfair or illicit means constitutes an act of misappropriation. Misappropriation may also include deriving commercial benefit from the acquisition or appropriation of traditional knowledge when the person using that knowledge knows, or is grossly negligent in failing to know, that it was acquired or appropriated by unfair means; and other commercial activities contrary to honest practices that gain inequitable benefit from traditional knowledge. ${ }^{6}$

This gives us a very broad understanding of misappropriation. One of the greatest difficulties is an appropriate definition of terms such as 'unfair' or 'illicit' and, perhaps most difficult, 'traditional knowledge', which would presumably come at the national level if or when these principles are utilised. ${ }^{7}$ The Draft Policy Objectives attempt to clarify in the next point that legal means should be available to suppress, amongst other things:

false claims or assertions of ownership or control over traditional knowledge, including acquiring, claiming or asserting intellectual property rights over traditional knowledge-related subject matter by a person who knew that the intellectual property rights were not validly held in the light of that traditional knowledge and any conditions relating to its access... ${ }^{8}$

\footnotetext{
4 TRIPS Council ‘Communication from Peru to the WTO' (7 November 2005).

5 WIPO IGC Secretariat, Protection of Traditional Knowledge: Overview of Policy Objectives and Core Principles, WIPO Doc WIPO/TKGRF/IC/7/5 (2004).

6 Ibid, annex II, 21.

7 G Dutfield, 'A Critical Analysis of the Debate on Traditional Knowledge, Drug Discovery and Patent-based Biopiracy' (2011) 33(4) European Intellectual Property Review 237. Dutfield makes the useful comment: 'What is traditional knowledge anyway? We only speak of traditional knowledge at all because there is knowledge in the world that we assume to be radically different from "our" knowledge. The latter we prefer to label as "modern" or "scientific" knowledge. Holding to a traditional-modern epistemological dualism as if all knowledge is either all of one or all of the other is in fact simplistic, misleading and unhelpful.'

8 WIPO IGC Secretariat, above n 5, annex I, 5.
} 
In this case we might ask: 'What is a false claim?' Is it, say, a claim that does not validly meet the requirements for a patent: novelty, invention and usefulness? Surely this is too narrow. Is it not possible to hold a valid patent that utilises traditional knowledge? Of course the answer is: 'Yes, it is possible', but these guiding principles would assert that prior informed consent would need to be obtained and benefits shared with the traditional knowledge holders in order to validate the patent.

These principles have been heavily debated in the IGC because of exactly these sorts of questions. What is probably lacking in these discussions is comparison against a suite of different examples that help distinguish what has been called misappropriation, but I will more specifically and usefully categorise as different typologies of biopiracy and misappropriation (see Box 1). The typologies are based on a review of various descriptions of biopiracy by academics and NGOs, as well as an examination of several biopiracy or bioprospecting incidents in the book Confronting Biopiracy. ${ }^{9}$ This chapter will then examine specific cases which align with this typology, and which highlight some of the key problems associated with the current suite of IP rules for the recognition of indigenous contributions to innovation.

\section{Box 1: Biopiracy and Misappropriation*}

\section{Patent-based Biopiracy}

The patenting of (often spurious) inventions based on biological resources and/ or traditional knowledge that are extracted without adequate authorisation and benefit sharing from other (usually developing) countries, indigenous or local communities.

\section{Non-patent Biopiracy}

Other IP control (through plant variety protection or deceptive trade marks) based on biological resources and/or traditional knowledge that have been extracted without adequate authorisation and benefit sharing from other (usually developing) countries, indigenous or local communities.

\section{Misappropriations}

The unauthorised extraction of biological resources and/or traditional knowledge for research and development purposes from other (usually developing) countries, indigenous or local communities, without adequate benefit sharing.

Note: 'Authorisation' involves obtaining (free) prior informed consent of the appropriate government authorities and, where relevant, local communities or other providers.

* Ibid, 21 [adapted].

In relation to patent-based biopiracy, it is worth noting that the patent claims are often spurious - what some might simply call 'bad patents'. However, this 
is not the limit of this form of biopiracy. Patents can legally be granted where the innovation is new and inventive, but can still be interpreted as biopiracy because they have not fulfilled the other legal and/or ethical conditions of prior informed consent and benefit sharing. Biopiracy is typically applied to cases from developing countries, but it is worth noting that biopiracy may also occur through the misappropriation and patenting (or other protection) of indigenous knowledge from communities residing in countries such as Australia, New Zealand, the US and Canada.

In addition to this typology, it is helpful to read the newly agreed scope of 'utilization of genetic resources' in the Nagoya Protocol to help decide what will be legal (which is a separate question from what is ethical). I have used the term 'biological resources' in my typology (written prior to the Nagoya Protocol) for two reasons. First, there is no traditional knowledge of 'genetic resources', but rather traditional knowledge exists in association with plants, animals and biological resources in the broader sense. I doubt that many would expect local communities to have been 'traditionally' examining genes through microarray. The term 'genetic resources' has been a red herring which developing countries and indigenous peoples have sought to enlarge, first with the Bonn Guidelines, and now more successfully with the Nagoya Protocol. Secondly, I use the broader term because many of the cases in which perceived injustices claimed as biopiracy or misappropriation have occurred relate to the utilisation of derivatives, extracts or biological materials in an R\&D context. Usefully, the Nagoya Protocol now assists in this understanding by expanding the definition of 'Utilization of genetic resources' in Article 2:

- 'Utilization of genetic resources' means to conduct research and development on the genetic and/or biochemical composition of genetic resources, including through the application of biotechnology ...

- 'Biotechnology' ... means any technological application that uses biological systems, living organisms, or derivatives thereof, to make or modify products or processes for specific use.

- 'Derivative' means a naturally occurring biochemical compound resulting from the genetic expression or metabolism of biological or genetic resources, even if it does not contain functional units of heredity.

This can be summarised to say that R\&D utilising biological resources and their biochemical derivatives for any technological application to make or modify products for specific (commercial) use must comply with the ABS provisions that the Nagoya Protocol will require of Parties. The key inclusions for the broadening of the scope of 'genetic resources', as previously narrowly defined in the CBD, are the broader definition of biotechnology and inclusion of references to the biochemical composition of genetic resources and derivatives (even if 
it does not contain functional units of heredity - DNA or RNA). Article 7 of the Protocol also clearly requires that domestic laws must have requirements for prior informed consent of traditional knowledge holders (indigenous and local communities) on mutually agreed terms (implying benefit sharing, which is discussed in Article 12) — an important addition to the Protocol.

In summary, this typology of biopiracy and misappropriation accords with the Nagoya Protocol. But the Protocol is silent on IP - a considerable problem for policy-makers and those confronting IP-related biopiracy cases.

The next step in this chapter is to challenge some misunderstandings about bioprospecting, biopiracy and misappropriation through specific case studies - real-world applications that often get forgotten in legal scholarship on these issues. In the following section, a specific focus on the idea of 'innovation', and a critique of IP rules for their inherent inability to adequately protect traditional knowledge, will be made through these case studies.

\section{Case Studies of Bioprospecting, Biopiracy and Misappropriation}

This section examines a number of cases that have been characterised as biopiracy or misappropriation, or questioned along these lines. They provide a useful point of examination regarding the way traditional knowledge may be used in the innovation process in different sectors (plant breeding, agriculture, medicines and cosmetics).

\section{(a) The Basmati Case - Plant Breeding and Innovation}

South Asia has a long history of domestication and breeding of rice. For example, archaeological evidence indicates that rice has been cultivated in India from between 1500 and $1000 \mathrm{BC} .{ }^{10}$ More specifically, basmati rice cultivars have been grown in South Asia, across India, Pakistan and also Bangladesh, probably for centuries, during which time they have been improved by local farmers through seed selection and conventional breeding practices. One of the earliest mentions of basmati is in the epic Heer and Ranjha composed in 1766. The most widely used rice variety - basmati 370 - was selected from local collections and released for commercial cultivation in 1933 at the Rice Research Station Kalashah Kaku (now Pakistan). ${ }^{11}$

10 M Rai, 'Genetic Diversity in Rice Production: Past Contribution and the Potential of Utilization for Sustainable Rice Production' in D Van Tran (ed), Sustainable Rice Production for Food Security: Proceedings of the 20th Session of the International Rice Commission. Bangkok, Thailand, 23-26 July 2002 (FAO, 2003).

11 V P Singh, 'The Basmati Rice of India' in R K Singh, U S Singh and G S Khush (eds), Aromatic Rices (Oxford and IBH Publishing, 2000) 135. 
The basmati rice 'biopiracy' controversy emerged in the late 1990s in response to a US patent. Specifically, the US Patent and Trademark Office (USPTO) granted patent number 5,663,484 on 'Basmati rice lines and grains' to the Texas-based company RiceTec Inc. on 2 September 1997. Originally the patent had twenty claims on the protected subject matter, covering the 'novel' basmati varieties that the researchers claimed to have developed. Unsurprisingly, this caused significant alarm and outrage amongst Indian farmers and NGOs. At the time, many interpreted the patent to mean an outright monopoly on basmati and thus restrictions on export to the US where the patent had been approved. As Ghosh notes, RiceTec's claims were for a specific rice plant (Claims 1-11, 14), for seeds that germinate the patented rice plant (Claim 12), for the grain that is produced by the rice plant (Claims 13, 15-17), and for the method of selecting plants for breeding and propagating particular grains of rice (Claims 18-20). ${ }^{12}$ The overly broad wording and scope of the patent can be blamed for much of the public outrage. ${ }^{13}$

Shortly after the patent was granted, Indian NGOs began a campaign against it, garnering support from the Indian government and drawing international attention to the patent. A re-examination application was filed by an organisation named the Agricultural and Processed Food Products Export Development Authority in India, with government support. ${ }^{14}$ Subsequently, RiceTec agreed to withdraw some claims, and under a re-examination certificate $(4525,29$ January 2002) these were formally retracted. Claims 1-7, 10 and 14-20 were cancelled, and descriptions of the rice were altered in the certificate. However, Claims 8, 9 and 11 for specific novel rice lines were maintained.

Analysis of the description in the patent document indicates that Claims 8, 9 and 11 refer to crossed rice lines (varieties) to develop plant varieties that exhibit some similar characteristics to basmati rice grains. Most countries in the world do not allow plant patents, but under US patent law novel plant varieties are eligible for protection. South Asian activists are particularly frustrated by this, because it appears that the germplasm used to cross the varieties was originally obtained from the region. The patent description for the breeding of BAS-867 and RT1117 rice lines indicates that:

Twenty-two basmati lines from the USDA World Germplasm Collection, Beltsville, Md. and thirteen semi-dwarf, long-grain lines were selected for the initial crosses ... The basmati seed from the USDA were identified as having come from Pakistan. ${ }^{15}$

12 S Ghosh, 'Globalization, Patents, and Traditional Knowledge' (2003-2004) 17(1) Columbia Journal of Asian Law 101.

13 Robinson, above $\mathrm{n} 9$

14 Ghosh, above n 12.

15 USPTO Patent Number 5,663,484. 
Activists such as Vandana Shiva have continued to argue that a simple crossbreed such as this is obvious to someone trained in plant breeding (and so it fails to achieve an inventive step), and that it is also not novel (new) because it free-rides on the existing prior art in the basmati rice's qualities. ${ }^{16}$ However, the US standards of novelty and obviousness failed to recognise the contributions of Indian farmers as applied by the USPTO. ${ }^{17}$ This brings us to our question about innovation: how is the plant breeding by the US researchers any more inventive than the breeding done by the South Asian farmers? The main difference is that one is a new cross-breed and the other is presumably a traditionally bred strain (improved slowly over generations through selection and more recent empirical breeding practices). But this does not negate the obviousness requirement, and we might well ask: 'Is the crossing of these specific cultivar lines for desirable traits an inherently obvious activity to someone trained in plant breeding?' Shiva thinks yes, and the innovation and IP policy-makers of many governments probably also agree. ${ }^{18}$ The answer comes down to jurisdiction: an 'inventive' crossed hybrid will be allowed under the US plant patent rules but not under many other patent systems. For many, the 'traditional' empirical breeding of a cultivar might be seen as just as inventive as modern crosses, albeit through a slower (but nevertheless systematic) process.

\section{(b) The Bolivian Habanero Pepper and Plant Variety Protection}

The previous example suggests a basic structural problem with the idea of 'plant patents' and the obviousness/inventiveness of plant varieties derived from different types of breeding practices. Here we examine the role of plant variety protection (PVP) as providing a similarly problematic structural incentive to free-ride on the breeding practices of others. In this case, a pepper (Capsicum chinense) cultivar was bred from a cross between an orange habanero pepper from the Yukatan Peninsula and a pepper from a US Department of Agriculture (USDA) gene bank with Plant Introduction (PI) number 543188 collected from Bolivia. This was then filed with the US Plant Variety Protection Office database with PVP number 200400329 for the 'TAM Mild Habanero Pepper' and issued in 2007.

16 V Shiva, Protect or Plunder: Understanding Intellectual Property Rights (Zed Books, 2001).

17 As some authors have noted, see S Kadidal 'United States Patent Prior Art Rules and the Neem Controversy: A Case of Subject-Matter Imperialism' (1998) 7(1) Biodiversity and Conservation 29. United States patent law does not recognise foreign prior art unless it is clearly documented and accessible. The geographical limitation on novelty is problematic in many biopiracy cases involving United States patents, particularly with regard to public knowledge or use of inventions in foreign countries which, in many cases, is orally transmitted rather than published or patented.

18 Shiva, above $\mathrm{n} 17$. 
The Texas A\&M University System Agriculture Program put out an 'AgNews' press release on the pepper on 12 August 2004, describing it as a successfully bred mild version of the infamously hot and piquant habanero pepper. From a five-year breeding programme, the progeny of a cross 'between a hot Yukatan habanero and a heatless habanero from Bolivia began to show promise'. ${ }^{19}$ Breeders from the Texas Agricultural Experiment Station have indicated their excitement at the possibility of selling the habaneros to salsa companies and as a fresh product at between $\$ 3$ and $\$ 4$ per pound, while the comparable jalapenos peppers fetch around 50 cents per pound. ${ }^{20}$

Here it is worth questioning whether the uniqueness of this mild habanero can be put down to the variety collected in Bolivia. The Texan breeders have obtained the germplasm from a USDA gene bank, and this is documented in the PVP certificate and admitted in their press release. The US Genetic Resources Information Network (GRIN) database record indicates that the original variety (GRIN PI 543188) is 'not piquant' and that it is 'said to be grown locally' in Bolivia. The records indicate that the original variety was purchased by a USDA official from a Brazilian vendor in the Cobija market of Nicolas Suarez Province (Pando Department) which borders Brazil on 13 November 1988. The plant material was then transferred to the USDA Plant Genetic Resources Conservation Unit in Georgia, and later accessed by the Texan breeders.

In this case a PVP certificate was obtained. It has different requirements from a plant patent. If this were a patent, an obviousness requirement might well have seen it rejected on the grounds that one of the parent plants contained substantially similar traits. Instead, there are requirements for the registered plant variety to be new, distinct, uniform and stable ${ }^{21}$ in order to receive twenty years of protection. This means that there is little to prove in terms of 'innovation' except for the distinctness of the plant:

The distinctness of one variety from another may be based on one or more identifiable morphological, physiological, or other characteristics (including any characteristics evidenced by processing or product characteristics, such as milling and baking characteristics in the case of wheat) with respect to which a difference in genealogy may contribute evidence. ${ }^{22}$

Conceivably, the cross-breeding may have changed the colour and look of the new variety from the original habanero. But in this case it appears that the most

19 R Santa Ana III, 'Texas Plant Breeder Develops Mild Habanero Pepper' AgNews - News and Public Affairs. Texas A\&M University System Agriculture Program (Texas), 12 August 2004.

20 Ibid.

21 Plant Variety Protection Act (PVPA) 7 USC $\S \S 2321-2582$ (1970), s 24(a).

22 Ibid, s 4l(b)(5). 
interesting or novel trait is that this habanero is non-piquant, a feature already present in the Bolivian parent - in all likelihood bred and 'grown locally' in Bolivia for exactly that trait. ${ }^{23}$ In terms of innovation, we again have to question whether the law in place - this time a PVP law — is appropriate in rewarding something as being unique or 'distinct' when in fact it may have only minor differences with the original or parent variety. Is this not just a case of allowing and legitimising free-riding on the 'traditional' innovation and breeding of Bolivians?

\section{(c) Artemisia judaica - The Limits of Traditional Knowledge}

It is worth pointing out that while traditional knowledge may make substantial contributions to the innovation process, it is also important not to overromanticise traditional knowledge. While those decrying biopiracy incidents are often pointing out failures in the ethical practices of bioprospectors and 'innovators', or the failings of both biological resources and IP laws, there are plenty of examples where they may overstate the injustice. ${ }^{24}$ US patent number $6,350,478$ on an 'Artemisia judaica fractionation method', which is registered by the UK company Phytotech Ltd (a subsidiary of PhytopharmPlc), is worth examining for exactly this purpose.

This patent became a topic of controversy following a report produced by the Washington DC-based NGO, the Edmonds Institute and the African Centre for Biosafety, called 'Out of Africa: Mysteries of Access and Benefit-Sharing' ${ }^{25}$ This report portrays the US patent in respect of Artemisia judaica as one of the mysteries of ABS. Notably, the plant Artemisia judaica has been used in Libya and other neighbouring North African and Middle Eastern countries as a traditional medicine. There is considerable documented prior art regarding the traditional medicinal uses of the plant, including treatments for diabetes. ${ }^{26}$

23 There are a number of documents that indicate the extent of breeding and use of cultivars of the Capsicum chinense species, including the habanero pepper in South and Central America. B Pickersgill, 'Relationships Between Weedy and Cultivated Forms in Some Species of Chili Peppers (Genus Capsicum)' (1971) 25 Evolution 683, indicates that archaeological excavations have placed sedentary people practising agriculture east of the Andes, possibly as early as $2000 \mathrm{BC}$, indicating that it was probably these people who first domesticated cultivars of the Capsicum chinense species. Articles such as those by M J McLeod et al,'Early Evolution of Chili Peppers (Capsicum)' (1982) 36 Economic Botany 361; P W Bosland, 'Capsicums: Innovative Uses of an Ancient Crop' in J Janick (ed), Progress in New Crops (ASHS Press, 1996) also indicate that the likely place of origin of the domesticated Capsicum chinense cultivars are the lowland Amazon Basin, with a potential range across Central America, South America and the Caribbean, see Robinson, above $\mathrm{n} 9$.

24 See, for example, Dutfield, above $n 7$.

$25 \mathrm{~J}$ McGown, Out of Africa: Mysteries of Access and Benefit Sharing (Edmonds Institute, Washington, and African Centre for Biosafety, 2006).

26 See C Z Liu et al,'Regeneration of the Egyptian Medicinal Plant Artemisia judaica L.' (2003) 21(6) Plant Cell Reports 525; T Dob and C Chelghoum, 'Chemical Composition of the Essential Oil of Artemisia judaica L. from Algeria' (2006) 21(2) Flavour and Fragrance Journal 343; H Azaizeh et al,'Ethnobotanical Knowledge of Local Arab Practitioners in the Middle Eastern Region' (2003) 74(1-2) Fitoterapia 99. 
McGown cites part of the patent description: 'Artemis judaica is used in Libyan traditional medicine as an infusion for the treatment of "wasting disease", almost certain[ly] dia[b]etes mellitus. ${ }^{27}$ But what he does not explain is that the patent in question covers only a series of methods for extraction of fractions from the Artemisia judaica plant - it is a process patent.

This raises an important question: can process patents really be called biopiracy? If we take the biopiracy typology above, a process patent does not qualify as patent-based biopiracy (but potentially fits the misappropriation depiction). However, in terms of a broader question of justice, process patents can still potentially be used to restrain a very wide array of research activity, especially if the invention claims are broadly described. The existence of the patent or the threat of lawsuits can stifle the interests of others, given that it is really beyond the costs of indigenous communities to challenge these patents in court. There are several examples where the threat of a lawsuit has deterred indigenous or local producers, including a kwao krua process patent in Thailand ${ }^{28}$ and the yellow enola bean example affecting Mexican producers. ${ }^{29}$

If we look to the Nagoya Protocol, the process patent does not raise any explicit conflict on its own. But presumably the researchers obtained the biological materials from Libya or a neighbouring country to conduct the research, and the way they extracted those materials is unknown. Surprisingly, the broader terms of the WIPO Draft Provisions description of misappropriation might depict this patent as such for 'deriving commercial benefit from the acquisition or appropriation of traditional knowledge'. However, we do not know if it was acquired through 'unfair' means.

In any case, there are important details in the patent itself that need further examination. The chromatographic fractions derived from this patented process are claimed to have 'non-mutagenic properties'. Other patent documents which cite the anti-diabetic properties of the Artemisia judaica plant ${ }^{30}$ note the presence of a 'deleterious mutagen' in crude extracts of the plant, which would make it unsuitable for the treatment of mammals and humans. It seems that traditional healers may have been using it without clear knowledge of the potential for mutagenic effects. ${ }^{31}$ While traditional knowledge has probably led scientists to this plant as a treatment for diabetes, the severe side-effects could be identified and removed only through modern scientific techniques - chromatographic

\footnotetext{
27 McGown, above n 26, 2.

28 Robinson, above n 9, 55.

29 Ibid, 51.

30 PCT Doc WO 97/35598; USPTO Patent Number 6,893,627.

31 Robinson, above n 9.
} 
analysis in this case. In this sense, both 'traditional medicine' and modern science needed each other to provide a useful and safe innovation (which in any case does not yet appear to have come to market).

According to patent rules, this innovation would appear to satisfy the novelty and non-obviousness requirements. What is less clear is the consent and benefitsharing process. As McGown points out, Phytopharm says that it maintains good agricultural practices to minimise environmental impacts by 'working with local agronomists and horticulturalists in each of the countries where we are growing crops'.$^{32}$ Yet the company does not specify further than this vague assurance. If the company does derive commercial benefit from this valid patent, then there is still a considerable argument for some sort of return benefit sharing to 'provider' groups for the partial contribution towards a useful end product.

\section{(d) White Kwao Krua - Yet Another Bad Patent?}

There have been a number of claimed patents over the Thai vine 'White Kwao Krua' (Pueraria mirifica) that have received considerable criticism in the Thai media. ${ }^{33}$ Some quite broad patents have been granted in the US and Japan on extracts of the plant used in compositions for treating the skin. For example, US patents with numbers 6,673,377 and 6,352,685 both claim an extract derived from Pueraria mirifica - a solvent and dry solid respectively - for use as a cosmetic ingredient that may help reduce wrinkles. These have received criticism with regards to novelty, obviousness, and use of biological resources and traditional knowledge without clear ABS procedures.

Yet another patent was granted in the US on 9 February 2010, with patent number 7,658,955 for 'Pueraria candollei var. mirifica A Shaw. \& Suvat. Extract'. The claims are on a process for obtaining a dry extract, and the extract itself, for use in a cosmetic application. The authors of the patent attempt to differentiate this from the other patents and from the traditional application by claiming a dry extract that does not cause eye irritation. The claims do not appear to be particularly inventive in light of the prior art in the field - the descriptions of traditional medicinal use and the other patents. The patent even recognises the traditional medicinal use of kwao krua:

For more than 500 years, people in South East Asia have been using the root of 'White Kwao Krua' for its profound anti-aging properties. This root has been identified as Puerariacandollei var. mirifica Airy Shaw et Suvat, which belongs to the family Papilionaceae (Leguminosae).

32 McGown, above n 26, 2.

33 D Robinson and J Kuanpoth, 'The Traditional Medicines Predicament: A Case Study of Thailand' (2009) 11(5-6) Journal of World Intellectual Property 375. 
However, they do not indicate whether they are the ones who identified the specific variant of the species - it seems highly unlikely that they are, and the variant is widely known in Northern Thailand. Figure 6 is a photo taken of 'White Kwao Krua' in Northern Thailand as identified by a Karen elder.

Figure 6. 'White Kwao Krua' as identified by Patthi Ta Yae, Baan Soplan, Samoeng, Chiang Mai, Thailand.

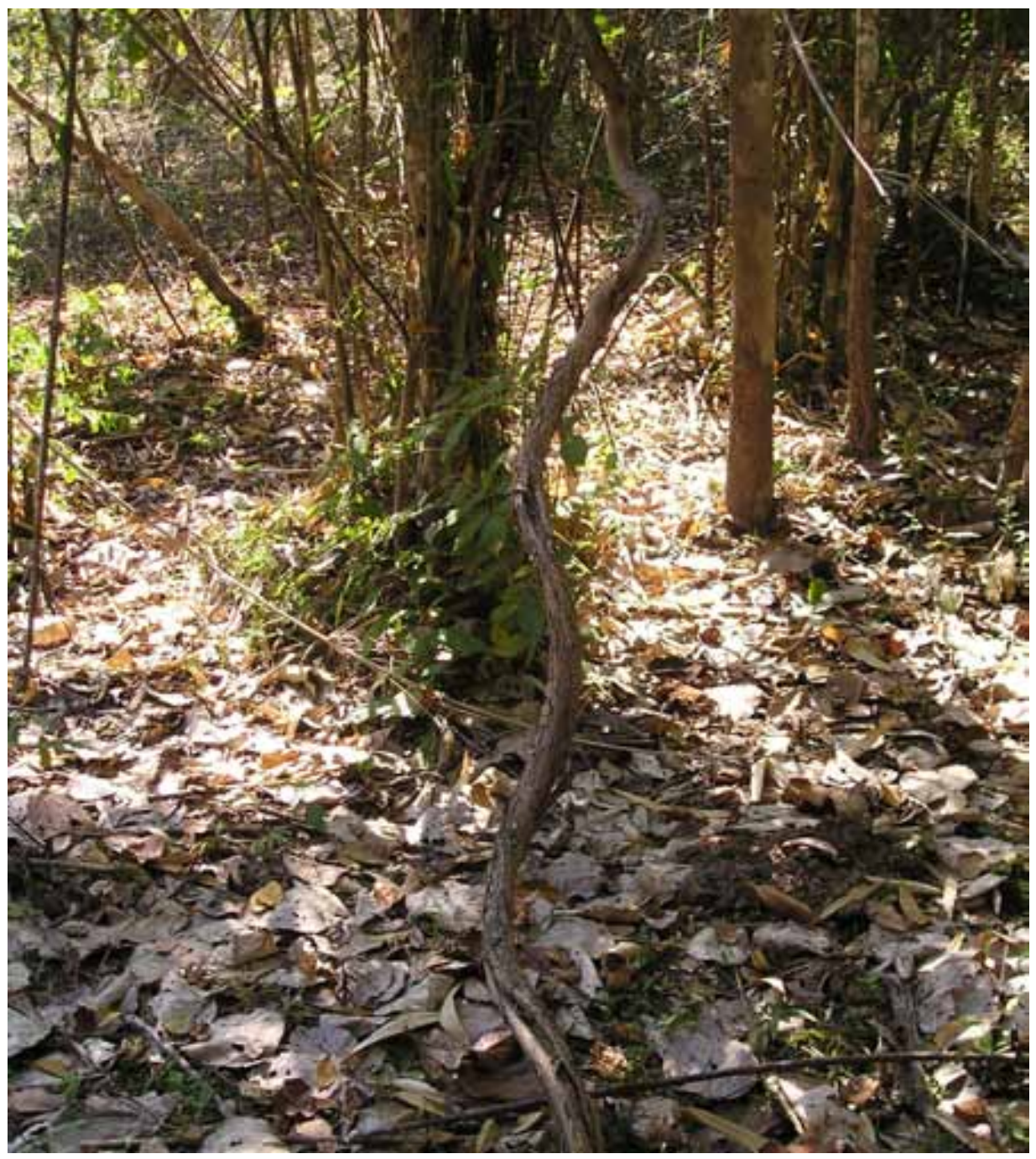

Source: D. Robinson 14 February 2006.

Their claim hinges on the extract of the specific variant of the Pueraria genus. They indicate: 'The only species with distinct estrogenic activity was found to be Pueraria candollei var. mirifica A. Shaw. \& Suvat (hereinafter Pueraria mirifica or P. mirifica).' They then contradictorily indicate that: 'The required species of 
the present invention is not "Pueraria mirifica" but Pueraria candollei var. mirifica A Shaw. \& Suvat.' One has to wonder if a patent examiner actually read this document before granting the patent.

If we do a simple search for existing literature about 'White Kwao Krua', many prior art documents appear, going back to 1931. In English, an article by Kashemsanta et al. from 1952 describes the identification of the species sent from Thailand to Kew Gardens: 'Pueraria mirifica Airy Shaw et Suvatabandhu, sp. Nov., P. Candollei Grah.' This is likely to be the same plant - in fact, the variant 'Airy Shaw and Suvathabandhu' is apparently named after two of the authors. The plant is also described by Cherdshewasart (one of the US patent holders of other kwao krua patents) and colleagues in two recent articles as 'Pueraria mirifica Airy Shaw et Suvatabandhu (synonymn: Pueraria candollei Wall. Ex Benth var mirifica (Airy Shaw \& Suvat)', which is likely to be a description of the same plant. ${ }^{34}$ These authors also note the identification of miroestrol, one of the phytoestrogens that is a key active of the plant, also listed as one of the key actives in the claims in the new US patent 7,658,955.

A few conclusions can be drawn from this case. First, there appear to be serious issues relating to prior art and obviousness in the case of this new patent. Secondly, all of these 'White Kwao Krua' patents are utilising traditional medicinal knowledge towards commercial gain - and they even acknowledge this. In these patents, the inventors have isolated the active ingredients certain phytoestrogens - and have altered dosage levels to improve safety for human usage. Yet none of this identification would have been possible without the contributions made by traditional Thai healers who have experimented with the plant and transmitted knowledge of it going back about a century (if not further). Certainly there is scope to make scientific improvements for the safe application of this herbal product as a cream. But are these patentable? Aren't the links between 'traditional medicine' and 'modern cosmetic' blindingly obvious and in need of adequate recognition? The Thai government has established ABS requirements (under their PVP Act) as well as a Thai Traditional and Alternative Medicines Act with the aim of ensuring that traditional medicines are appropriately promoted and protected. To date it does not appear that there are any ABS arrangement between the researchers and the Thai government in relation to this plant. In the meantime, the white kwao krua plant has been heavily poached from forest areas as a result of recent public demand, highlighting the importance of ABS contributions to the conservation of useful species.

34 W Cherdshewasart et al, 'The Differential Anti-proliferation Effect of the White (Pueraria mirifica), Red (Butea superba) and Black (Mucuna collettii) Kwao Krua Plants on the Growth of MCF-7 Cells' (2004) 93 Journal of Ethnopharmacology 255; W Cherdshewasart and W Sutjit, 'Correlation of Antioxidant Activity and Major Isoflavonoid Contents of the Phytoestrogen-rich Pueraria mirifica and Pueraria lobata tubers' (2008) 15(1-2) Phytomedicine 38. 


\section{Conclusions}

In three of the four cases discussed, the United States IP system, whether through patents or plant variety protection, has provided monopoly protection for 'innovations' that are incremental at best. The Artemisia case, although making an apparently more substantial inventive contribution, still has shortened its $\mathrm{R} \& \mathrm{D}$ process through the use of traditional knowledge (relating to diabetes treatment, although also potentially severe in its side-effects). The Artemisia case does, however, indicate that scientific and traditional innovation systems can interact in mutually beneficial ways. What is important is that the terms of the exchange between different parties is 'fair and equitable'. Indeed, there are more cases emerging wherein researchers or companies have successfully established mutually beneficial arrangements with indigenous communities (for example, the commercial use of Argan oil for cosmetics by Cognis and L'Oreal). ${ }^{35}$

However, what is frustrating about the cases described in this chapter (and in many other biopiracy cases) is that the 'traditional' contribution to the innovation is poorly recognised at best (as in the kwao krua case) and completely ignored in others. If we stopped thinking of the indigenous peoples' contributions as 'traditional knowledge' and formally recognised 'indigenous innovation', we may well find some patents and plant variety certificates are never actually granted because of their lack of novelty. We may find that inventiveness and obviousness are perceived differently if patent examiners are able to peer through the guise of 'technical' language to see that the wheel is being continually re-invented. For example:

- The remaining patented basmati rice lines could not be produced without the long-term breeding innovations of South Asia farmers.

- The protected cross-breed of habanero pepper almost certainly would not have such unique traits without the breeding contributions of Bolivian farmers.

- The Artemisia researchers would not have identified the plant as a diabetes treatment without the use of traditional medicinal knowledge (albeit apparently unaware of mutagenic effects).

- The white kwao krua plant would not continually be re-processed in different forms to serve the same purpose - as a cosmetic that reduces wrinkles without the experimentation of Thai healers.

This highlights the importance of initiatives such as the Traditional Knowledge Digital Library (TKDL) which is clearly starting to make an impression on the

35 D F Robinson and E Defrenne, Argan: A Case Study on ABS? (2011) <http://www.ethicalbiotrade.org/dl/ UEBT_D_ROBINSON_AND_E_DEFRENNE_final.pdf> 
minds of examiners in the European Patent Office and Canadian Intellectual Property Office, with several patents withdrawn or set aside due to the influence of the TKDL. While this is an important achievement on its own, this initiative is likely to stop only patent-based biopiracy or 'bad patents', and will not prevent misappropriations or non-patent biopiracy, or provide mechanisms for the active promotion of the innovations of indigenous and local communities.

Drahos has made useful suggestions towards a treaty on Traditional Group Knowledge and Practice (TGKP). ${ }^{36}$ He suggests in his conclusions that a treaty should focus on the enforcement dimension of TGKP, being modest in setting substantive standards but strong on coordinating national enforcement activities for the prevention of misappropriation of traditional knowledge through a Global Bio-Collecting Society. Given that there have been some considerable successes at the national level in Peru with the establishment of an 'Anti-Biopiracy Commission' which has investigated and lobbied for the successful withdrawal of several foreign patents that utilised biological resources and associated traditional knowledge or innovation, such a concept might prove useful if expanded internationally (at least for preventing patentbased biopiracy). Irrespective of whether an international system is in place, the development of national biopiracy and/or misappropriation ombudsmen would be a useful step for countries in which it has been a persistent problem. In fact, this idea was raised in the ABS negotiations prior to Nagoya, but was unfortunately dropped late in the negotiations in order to reach a compromise.

Despite some flaws, the Nagoya Protocol is an obvious step towards positive outcomes of ABS, and will hopefully result in some benefits for 'traditional knowledge holders' and for conservation, as well as adequate respect for their contributions through prior informed consent procedures. What might also be useful are suigeneris systems for the protection and promotion of the innovations of indigenous peoples and local communities that are less prescriptive than IP laws and which reflect customary mechanisms of protection. However, the promise of custom-based sui generis systems is likely to be also hamstrung by the jurisprudential diversity of the many indigenous groups around the world. ${ }^{37}$

Lastly, while it might seem biased to square this criticism directly at the US (which is certainly not the only country guilty of allowing or legitimising biopiracy), the USPTO has consistently proven itself to be an open door for anything remotely resembling an invention. As Quillen and Webster note,

36 P Drahos, 'Towards an International Framework for the Protection of Traditional Group Knowledge' (Report from UNCTAD-Commonwealth Secretariat Workshop on Elements of National Sui Generis Systems for the Preservation, Protection and Promotion of Traditional Knowledge, Innovations and Practices and Options for an International Framework, Geneva, 4-6 February 2004).

37 A Taubman, 'Saving the Village: Conserving Jurisprudential Diversity in the International Protection of Traditional Knowledge' in K E Maskus and J H Reichman (eds), International Public Goods and Transfer of Technology Under a Globalised Intellectual Property Regime (Cambridge University Press, 2005) 521. 
average grant rates were around 67 per cent at the European Patent Office (EPO) and 64 per cent at the Japanese Patent Office (JPO) for the period 1995-99, while at the USPTO the grant rate was found to be between 87 and 97 per cent during 1993-98, including continuation applications - essentially re-filings of existing applications. ${ }^{38}$ The United States is also one of the only remaining countries in the world yet to ratify the CBD. With the agreement of the Nagoya Protocol, the rest of the world is now preparing to implement a comprehensive international regime on ABS, which will have one glaring absentee. We must let the US Government know that this is unacceptable.

38 C D Quillen and O H Webster, 'Continuing Patent Applications and Performance of the United States Patent Office' (2001) 11(1) Federal Circuit Bar Journal 1; C Martinez and D Guellec, 'Overview of Recent Changes and Comparison of Patent Regimes in the United States, Japan and Europe' in OECD, Patents, Innovation and Economic Performance: OECD Conference Proceedings (OECD, 2004) 144. 